\title{
TREATMENT OUTCOMES \\ OF PERI-ARTICULAR STEROID INJECTION FOR PATIENTS WITH WORK-RELATED SACROILIAC JOINT PAIN AND LUMBAR PARA-SPINAL MUSCLE STRAIN
}

\author{
KHALID MEDANI ${ }^{1}$, KUSHINGA BVUTE ${ }^{2}$, NATASHA NARAYAN ${ }^{1}$, CESAR REIS ${ }^{1}$, and AKBAR SHARIP ${ }^{1}$ \\ ${ }^{1}$ Loma Linda University Medical Center, Loma Linda, CA, USA \\ Department of Occupational Medicine \\ ${ }^{2}$ Loma Linda University, Loma Linda, CA, USA \\ School of Public Health
}

\begin{abstract}
Objectives: Evaluating treatment outcomes of local corticosteroid injections for work-related lower back pain (LBP) as the current evidence for the American College of Occupational and Environmental Medicine guidelines is considered insufficient to recommend this practice. Material and Methods: The authors conducted a retrospective study involving the patients who were treated with peri-articular and lower lumbar corticosteroid injections for work-related LBP at their occupational medicine clinic. Results: Sixty-four patients met the inclusion criteria. The average pain level was reduced from $\mathrm{M} \pm \mathrm{SD} 5.1 \pm 2.0$ to $\mathrm{M} \pm \mathrm{SD} 3.1 \pm 2.3$ after the corticosteroid injection $(\mathrm{p}<0.0001)$. Thirty-five patients $(55 \%)$ were discharged to regular duty; 23 (36\%) were transferred to orthopedics due to persistent pain; and $6(9 \%)$ were lost to follow-up. Conclusions: Corticosteroid injections for work-related LBP are effective in reducing pain and enhancing discharge to regular duty. Nonetheless, larger prospective trials are needed to validate these findings. Int J Occup Med Environ Health. 2021;34(1):111-20
\end{abstract}

Key words:

sacroiliac joint pain, peri-articular steroid injection, trigger point injection, lumbar strain, para-spinal muscle strain, work-related low back pain

\section{INTRODUCTION}

Low back pain (LBP) is a public health concern in the workplace, and most workers are expected to experience symptoms of LBP during their working life [1]. Back pain is the second leading cause of disability among American adults [2]. The 2010 Global Burden of Disease Study estimated that LBP is among the top 10 diseases and injuries that account for the highest number of disability-adjust- ed life years (DALYs) worldwide [3]. In 2010, the global point prevalence of LBP was 9.4\% (95\% confidence interval (CI): 9.0-9.8), while DALYs had increased by $42.6 \%$, from 58.2 million (95\% CI: 39.9 million-78.1 million) in 1990 to 83.0 million (95\% CI: 56.6 million-111.9 million) in 2010.

Occupational LBP represents a substantial economic and social burden [4]. Lower back pain is the most common

Received: January 20, 2020. Accepted: October 5, 2020.

Corresponding author: Khalid Medani, Loma Linda University Medical Center, Department of Occupational Medicine, 328 E Commercial Rd, San Bernardino, CA 92408, USA (e-mail: khmedani@gmail.com). 
cause of job-related disability [5]. Affected employees experience limited activity, a loss of productive time, and absenteeism from work, thus imposing a high economic burden on individuals, families, communities, industry, and governments [5]. In the USA, $25.7 \%$ of all workers, $23.8 \%$ of workers aged $18-40$ years, and $27.7 \%$ of workers aged 41-64 years experience back pain, costing the healthcare industry USD 50-90.7 billion yearly [6]. In 2016, the total workers' compensation benefits paid were USD 61.9 billion, and the employers' costs for workers' compensations were USD 96.5 billion [7], equivalent to $0.85 \%$ of the 2016 GDP. In addition, low back disorders are disproportionately expensive, accounting for 10-33\% of U.S. workers' compensation costs [8-10]. Although two-thirds of LBP cases return to work within 1 month, about $17 \%$ and $7 \%$ of such cases experience work disability for 1-6 months and for $>6$ months, respectively [11].

The 2016 Low Back Disorders Guidelines released by the American College of Occupational and Environmental Medicine (ACOEM) [12] classify LBP as acute $(<1$ month duration), subacute (1-3 month duration) and chronic ( $>3$ month duration). The first-line recommended medication for acute, subacute and chronic LBP are generic non-steroidal anti-inflammatory drugs (NSAIDs) such as ibuprofen or naproxen, in combination with non-pharmacological interventions such as physical therapy [12]. The first-line interventions lead to an improvement in the majority of patients. Secondline medications include one of the other generic NSAIDs, while ACOEM recommends cyclooxygenase-2 (COX-2) selective inhibitors as third-line medications. The ACOEM guidelines moderately recommend muscle relaxants as the secondline treatment for moderate-to-severe acute LBP inadequately controlled by NSAIDs. The guidelines do not address new work-related LBP injuries for patients with pre-existing back injuries and back pain, yet in real life many work-related lower back injury patients have pre-existing LBP.

If conservative treatment does not provide symptoms relief, more invasive treatments are generally consid- ered [13]. Although the ACOEM guidelines recommend local anesthetics for trigger point injections, they do not recommend corticosteroid injections. Corticosteroids have anti-inflammatory properties that help to reduce pain [14]; however, the recent ACOEM guidelines consider steroid injections for acute low back or sacroiliac joint (SIJ) pain as "not-recommended - class (I)" (where A - strongly not-recommended, B - moderately not-recommended, C - not-recommended, and I - insufficiently not-recommended). The steroid injection for trigger points (points of maximum tenderness) for LBP is also considered "notrecommended - class (C)". Notably, ACOEM based their rationale for not recommending trigger point steroid injections on the absence of quality studies evaluating these injections for acute LBP and a lack of studies that would evaluate the efficacy of the injections for LBP on a longerterm basis [12].

The pathophysiology of non-radicular LBP is usually nonspecific. Pain can arise from a number of sites, including the vertebral column, surrounding para-spinal muscles, tendons, ligaments, and fascia. Thiese et al. [15] investigated the anatomical locations of LBP among the working population. The researchers classified the area of LBP into 5 anatomical regions: immediate para-spinal, left and right lateral lumbar, and left and right gluteal areas. The study found that about $76 \%$ of LBP cases arose in the immediate para-spinal area. Additionally, about $40 \%$ of the participants reported pain in $>1$ region [15].

It was found that 15-25\% of LBP cases arise from SIJ [16]. However, the causes of SIJ involvement are diverse, and the diagnosis is often challenging [17]. In fact, SIJ disease is hard to confirm in clinical settings, and there are insufficient data to support any single diagnostic provocative test. While 15 publications have addressed the therapeutic effectiveness of SIJ injections, 1 clinical trial on 13 SIJs showed statistically and clinically significant improvements with the corticosteroid injection, although its validity was uncertain [18]. The ACOEM guidelines do not 
describe the treatment outcomes for patients who receive both the trigger point and SIJ steroid injections. There is a need to assess the effectiveness of an approach that takes into account the clinical diagnostic challenges of SIJ disease and the high prevalence of work-related LBP in the para-spinal lumbar region.

Currently, ACOEM does not recommend SIJ steroid injections since previous studies where confined to populations with spondyloarthropathy, and the data were not applicable to the working population. Based on the abovestated facts, there is a need for further studies on the efficacy of SIJ steroid injections on the working population.

The objective of this study is to evaluate the treatment outcomes of trigger point and SIJ steroid injections for patients with work-related acute, subacute and chronic LBP and SIJ pain, who have not responded to conservative treatment, by assessing changes in pain levels, and time to discharge.

\section{MATERIAL AND METHODS}

The Institutional Review Boards of Loma Linda University approved this study. The authors conducted a retrospective follow-up study of data collected from the electronic medical records of the patients seen at the Loma Linda Occupational Medicine Clinic in April 2013-March 2018. They identified cases using the International Classification of Diseases (ICD), both ICD-9 and ICD-10 codes, for lumbar strain, low back strain, sacroiliac dysfunction and sacroiliac sprain, who had received peri-articular SIJ or lower lumbar para-spinal muscle triamcinolone injections. They excluded cases with a history of fibromyalgia. The patients rated their pain level using the Visual Analogue Scale.

The authors analyzed the data of the entire cohort and assessed the differences in the treatment outcomes before and after the steroid injection. They looked for any differences in the treatment outcomes between the patients with pre-existing back pain and those without pre-existing back pain. They then compared the differences of the treatment outcomes between the patients who had received the injection within 30 days (acute LBP), between 31-90 days (subacute LBP) and after 90 days (chronic LBP) by stratifying the data according to the time interval between the day of the injury and the day of the steroid injection. The dataset included basic demographic details. The authors captured dates of the injury, the initial visit, the subsequent follow-ups and the day of the steroid injection. They noted the use of NSAIDs, muscle relaxants and narcotics, and the number of physical therapy sessions completed before the steroid injection. In addition, they documented the day of discharge or referral to orthopedics.

\section{Intervention}

Steroid injections for LBP can be delivered with or without imaging guidance (such as fluoroscopy or ultrasound). In this study, the authors performed these injections depending only on the anatomical landmarks. The posterior superior iliac spine was used to identify the area of the injections (Figure 1). The authors used a 22-gauge 2" or a 3.5" spinal needle (depending on the size of the patient) to inject the medication into the SIJ and the peri-articular joint space with subsequent redirection of the needle to the area of maximal tenderness at the para-spinal muscles. The injection solution was composed of triamcinolone at a dose of $20-40 \mathrm{mg}$ (0.5-1 ml) mixed with $0.5-4 \mathrm{ml}$ of $2 \%$ plain lidocaine with or without $0.5 \%$ bupivacaine. Written consent was obtained and standard precautions of trigger point steroid injections were applied in the maneuver.

\section{Statistical analysis}

The authors used SAS ${ }^{\circledast} 9.4$ for the data analysis. They performed a paired t-test (Figures $2 \mathrm{a}$ and $2 \mathrm{~b}$ ) to evaluate the difference in the pain levels on the day of the steroid injection and 1 week after the injection. The paired t-test was also used to compare the difference in the pain levels on the day of the injection and on the day of discharge. A p-value of $<0.05$ was considered statistically significant. 


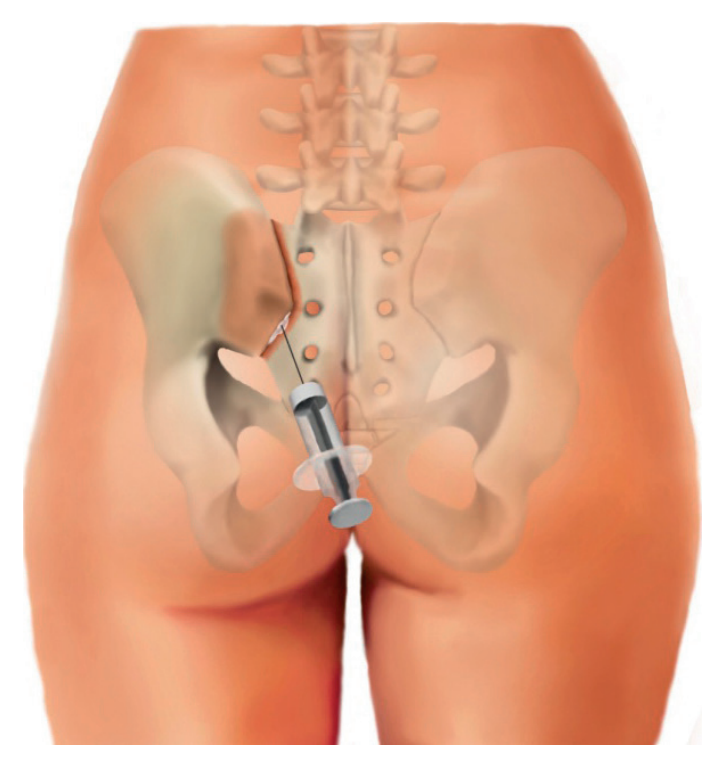

Figure 1. Sacroiliac joint steroid injections in the peri-articular space

\section{RESULTS}

The authors identified a total of 64 patients who fit into their study criteria. The median age was 40 years (range: 18-70 years). Seventy percent of the study population were women; 62 patients $(97 \%)$ used NSAIDs while $58(91 \%)$ received muscle relaxants (cyclobenzaprine or methocarbamol) before the steroid injection; 35 patients $(55 \%)$ used narcotics (acetaminophen with codeine, tramadol, hydrocodone or oxycodone) (Table 1), and $53(83 \%)$ had received $\geq 1$ physical therapy session(s) before the steroid injection. The median waiting time from the date of the injury to the date of the injection was 42 days (range: 1-394 days). The first follow-up after the steroid injection was scheduled in a median of 1 week (range: 1-6 weeks). The average initial pain level for all patients on their first visit to the clinic was $\mathrm{M} \pm \mathrm{SD} 6.3 \pm 2.1$. The average pain level on the day of the injection was $\mathrm{M} \pm \mathrm{SD}$ 5.1 \pm 2.0 , while the average pain level for the patients at the first follow-up visit after the steroid injection was $\mathrm{M} \pm \mathrm{SD} 3.1 \pm 2.3$. The difference in the average pain levels between the day of the intervention and the first follow-up visit after the injection was statistically significant (a p-value for the paired t-test of <0.0001). The overall mean duration of follow-up was $\mathrm{M} \pm$ SD $126 \pm 94$ days.

Among those patients, 35 patients (55\%) were subsequently discharged, $23(36 \%)$ were transferred to orthopedic surgery due to persistent symptoms despite steroid injections and other interventions, and $6(9 \%)$ were lost to follow-up. Figure 3 demonstrates the study flow chart. The average pain level on the day of discharge for the discharged group was $0.4 \pm 0.8$. The average pain level on the transfer day for the transferred group was $4.3 \pm 2.1$. The difference in the average pain levels between the day of the steroid injection and the day of discharge in the discharged group was statistically significant (a p-value for the paired t-test of $<0.0001)$. The difference in the average pain levels between the day of the steroid injection and the day of the transfer in the transferred group was also statistically significant (a p-value for the paired t-test of 0.038). However, the magnitude of significance was smaller compared to the discharged group (0.038 vs. $<0.0001)$.

Among the 64 patients involved in this study, $8(13 \%)$ had pre-existing LBP (PLBP). The average pain level for PLBP was $3.8 \pm 1.3$, and the average duration of PLBP was $3.7 \pm 4.8$ years. The average waiting time from the day of the new injury to the day of the steroid injection for PLBP was $19.1 \pm 17.2$ days compared to $67.2 \pm 70.0$ days for the patients without PLBP. The difference in waiting time between the 2 groups was statistically significant (a p-value of <0.0001). The mean total duration of the follow-up was shorter by 34.5 days for PLBP; however, this difference was not statistically significant $(p=0.42)$. The transfer rates between the patients with PLBP or LBP were not statistically significant. The difference in the average pain level on the day of discharge for PBLP was not significantly different from those without $\operatorname{PLBP}(p=1)$.

The authors classified the patients into groups based on the interval between the day of the injury and the day of the steroid injection; acute LBP (within 30 days), subacute LBP (31-90 days) or chronic LBP (after 90 days). There 
Table 1. Characteristics of the patients who received a sacroiliac joint steroid injection in April 2013-March 2018 at the Loma Linda University Medical Center, Loma Linda, USA

\begin{tabular}{|c|c|c|c|c|}
\hline \multirow{3}{*}{ Variable } & \multicolumn{4}{|c|}{$\begin{array}{l}\text { Participants } \\
(\mathrm{N}=64)\end{array}$} \\
\hline & \multirow[b]{2}{*}{ total } & \multicolumn{3}{|c|}{ with LBP } \\
\hline & & $\begin{array}{c}\text { acute } \\
(\mathrm{N}=24,38 \%)\end{array}$ & $\begin{array}{c}\text { subacute } \\
(\mathrm{N}=26,41 \%)\end{array}$ & $\begin{array}{c}\text { chronic } \\
(\mathrm{N}=14,22 \%)\end{array}$ \\
\hline Age [years] (Me (range)) & $40(18-70)$ & $35(22-70)$ & $44(25-64)$ & $45(18-59)$ \\
\hline Women $[\mathrm{n}(\%)]$ & $45(70)$ & $18(75)$ & $17(65)$ & $10(71)$ \\
\hline Pre-existing back injury [n (\%)] & $26(41)$ & $12(50)$ & $9(35)$ & $5(36)$ \\
\hline \multicolumn{5}{|l|}{ Treatment modalities before the injections } \\
\hline NSAIDs [n (\%)] & $62(97)$ & $23(96)$ & $25(96)$ & $14(100)$ \\
\hline muscle relaxants [n (\%)] & $58(91)$ & $19(79)$ & $25(96)$ & $14(100)$ \\
\hline $\operatorname{narcotics}[\mathrm{n}(\%)]$ & $35(55)$ & $14(58)$ & $15(58)$ & $6(43)$ \\
\hline $\begin{array}{l}\text { physical therapy sessions performed [n] } \\
\text { (Me (range)) }\end{array}$ & & $6.5(0-12)$ & $6(0-13)$ & $6(0-12)$ \\
\hline \multicolumn{5}{|l|}{ Subjective clinical measures } \\
\hline pre-existing back pain [n (\%)] & $8(13)$ & $6(25)$ & 2(8) & 0 \\
\hline \multicolumn{5}{|l|}{ back pain level (VAS) $(\mathrm{M} \pm \mathrm{SD})$} \\
\hline initial & $6.3 \pm 2.1$ & $6.6 \pm 2.1$ & $6.0 \pm 2.0$ & $6.3 \pm 2.2$ \\
\hline on the day of the injection & $5.1 \pm 2.0$ & $5.3 \pm 2.1$ & $5.0 \pm 2.1$ & $5.0 \pm 1.7$ \\
\hline $\begin{array}{l}\text { at the first follow-up visit (a median of } 1 \text { week) } \\
\text { after the steroid injection }\end{array}$ & $3.1 \pm 2.3$ & $3.6 \pm 2.7$ & $2.8 \pm 2.1$ & $2.8 \pm 1.9$ \\
\hline $\begin{array}{l}\text { on the day of discharge for the discharged group } \\
(\mathrm{N}=35)\end{array}$ & $0.4 \pm 0.8$ & $0.4 \pm 1$ & $0.3 \pm 0.9$ & $0.4 \pm 0.7$ \\
\hline $\begin{array}{l}\text { on the day of transfer to orthopedics } \\
\text { for the transferred group }(\mathrm{N}=23)\end{array}$ & $4.3 \pm 2.1$ & $4.4 \pm 2.6$ & $4.5 \pm 1.4$ & $3.7 \pm 2.5$ \\
\hline \multicolumn{5}{|l|}{ Follow-up [days] (Me (range)) } \\
\hline \multicolumn{5}{|l|}{ the steroid injection group } \\
\hline prior to (waiting time) $(\mathrm{N}=64)$ & $42(1-394)$ & $15(1-29)^{*}$ & $50(32-86)^{*}$ & $118(91-394)^{*}$ \\
\hline post $(\mathrm{N}=64)$ & $45(0-328)$ & $41(14-328)$ & $51(7-312)$ & $43(0-112)$ \\
\hline total (before and after steroid injection) $(\mathrm{N}=64)$ & $87(26-481)$ & $57(26-352)^{*}$ & $118(48-362)^{*}$ & $175(117-481)^{*}$ \\
\hline \multicolumn{5}{|l|}{ the discharged group } \\
\hline post-steroid injection $(\mathrm{N}=35)$ & $42(0-328)$ & $37(14-328)$ & $52(13-217)$ & $34(0-112)$ \\
\hline $\begin{array}{l}\text { total (before and after the steroid injection) } \\
(\mathrm{N}=35)\end{array}$ & $120(34-481)$ & $53(34-352)^{* *}$ & $118(49-277)^{* *}$ & $162(120-481)^{* *}$ \\
\hline \multicolumn{5}{|l|}{ the transferred group } \\
\hline post-steroid injection $(\mathrm{N}=23)$ & $47(7-312)$ & $44(20-78)$ & $41(7-312)$ & $79(21-90)$ \\
\hline $\begin{array}{l}\text { total (before and after the steroid injection) } \\
(\mathrm{N}=23)\end{array}$ & $77(26-362)$ & $70(26-86)$ & $79(48-362)$ & $176(117-187)$ \\
\hline
\end{tabular}


Table 1. Characteristics of the patients who received a sacroiliac joint steroid injection in April 2013-March 2018 at the Loma Linda University Medical Center, Loma Linda, USA - cont.

\begin{tabular}{|c|c|c|c|c|}
\hline \multirow{3}{*}{ Variable } & \multicolumn{4}{|c|}{$\begin{array}{l}\text { Participants } \\
(\mathrm{N}=64)\end{array}$} \\
\hline & \multirow[b]{2}{*}{ total } & \multicolumn{3}{|c|}{ with LBP } \\
\hline & & $\begin{array}{c}\text { acute } \\
(\mathrm{N}=24,38 \%)\end{array}$ & $\begin{array}{c}\text { subacute } \\
(\mathrm{N}=26,41 \%)\end{array}$ & $\begin{array}{c}\text { chronic } \\
(\mathrm{N}=14,22 \%)\end{array}$ \\
\hline \multicolumn{5}{|l|}{ Treatment outcome (n $[\%])$} \\
\hline referred to orthopedics & $23(36)$ & $10(42)$ & $10(38)$ & $3(21)$ \\
\hline lost to follow-up & $6(9)$ & $4(16)$ & $1(4)$ & $1(7)$ \\
\hline discharged & $35(55)$ & $10(42)$ & $15(58)$ & $10(71)$ \\
\hline
\end{tabular}

$* \mathrm{p}<0.001, * * \mathrm{p}<0.05$

LBP - low back pain; NSAIDs - non-steroidal anti-inflammatory drugs; VAS - Visual Analogue Scale.

were 24 acute (38\%), 26 subacute (41\%), and 14 chronic (22\%) LBP patients (Figure 3). There was no statistical difference in the mean age, gender distribution or the initial pain levels between the 3 groups (Table 1). The difference in the use of NSAIDs, muscle relaxants and narcotics among the 3 groups was not significant. The higher prevalence of pre-existing pain for acute LBP $(25 \%)$ was borderline significant compared to $8 \%$ and $0 \%$ for the subacute and chronic LBP, respectively ( $p=0.05$ ) (Table 1); however, the difference in transfers and pain on the day of discharge was insignificant. The authors discharged $71 \%$ of chronic LBP patients, compared to $58 \%$ and $42 \%$ of subacute and acute LBP patients, respectively. The average pain levels decreased for all groups, with 52 patients (81\%) reporting an improvement in the pain level 1 week after the intervention (Figures 2a and 2b). The median duration of followup after the steroid injection was 42 days to the day of discharge and 47 days to the day of transfer. None of these patients reported significant side effects or complications.

Subgroup analysis was further done to compare the baseline characteristics, the clinical status and radiological findings between the discharged and transferred groups. The authors found no statistically significant difference in the body mass index (BMI), age, gender, tobacco use or a history of mental illness between the discharged and transferred patients (Table 2). Additionally, the initial pain level, the duration of symptoms prior to the steroid injection and the use of narcotic medications were not different between the 2 groups. However, the transferred group had a significantly higher positive findings in their magnetic resonance imaging (features of the lumbar spine degenerative disc disease) when compared to the discharged group $(\mathrm{p}=0.016)$ (Table 2).

\section{DISCUSSION}

This study describes the therapeutic approach to treating occupational LBP with the use of corticosteroid injections for patients whose symptoms do not respond to conservative treatment. The average median follow-up duration after the steroid injection for all the patients involved in the study was 45 days. Notably, $55 \%$ of the patients reported significant improvements and were subsequently discharged; $36 \%$ were transferred to orthopedic surgery due to persistent symptoms; and $81 \%$ had signs of improved symptoms at least in the short- or intermediate-term follow-up. These findings indicate that corticosteroids combined with local anesthetic injections are generally safe and effective in improving symptoms at least for the intermediate-term follow-up (6 months after discharge). 


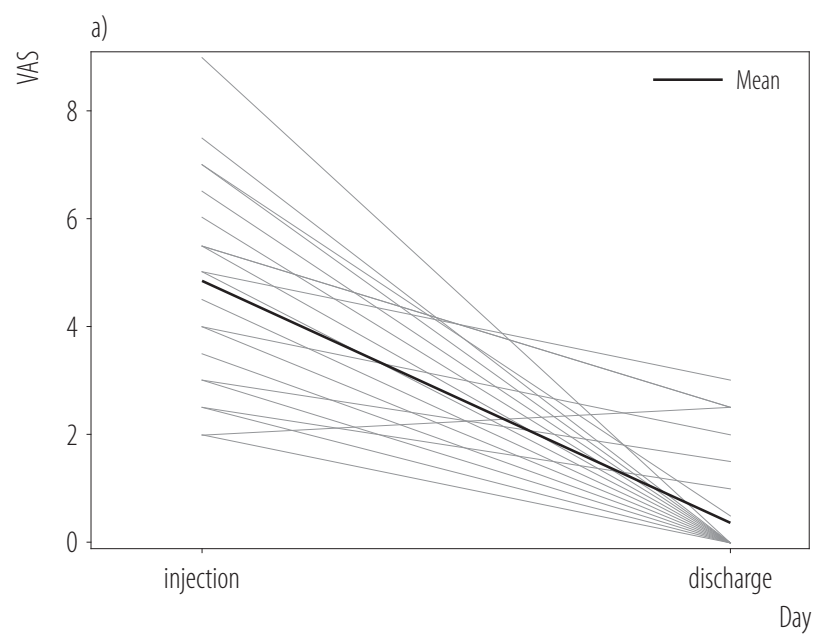

Follow-up median $=6$ weeks.

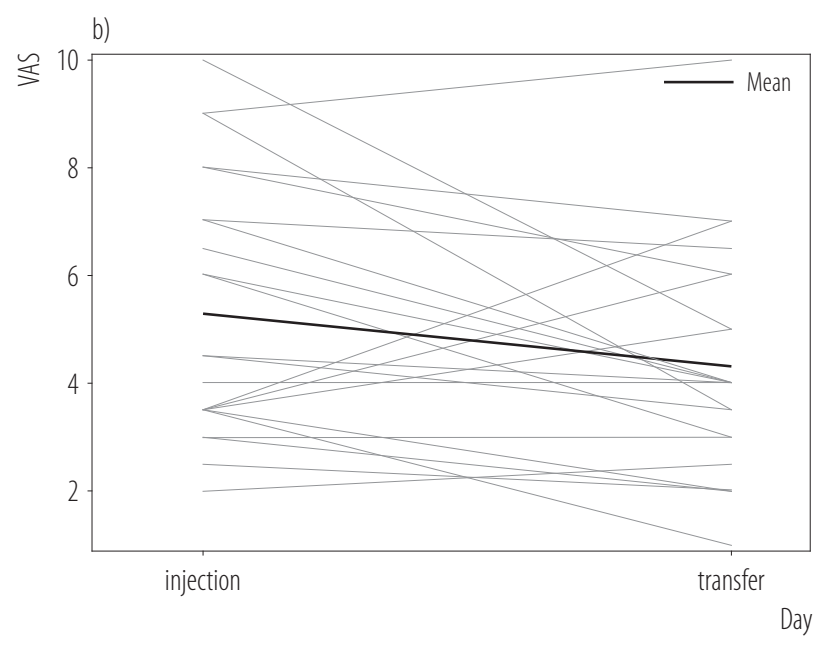

Follow-up mean $=6.7$ weeks.

Figure 2. A paired t-test for the difference in the pain levels (measured by the Visual Analogue Scale) between the day of the injection and the day of a) discharge $(\mathrm{N}=35)$ and b) transfer $(\mathrm{N}=23)$

Plausible explanation for these findings is that the steroid solution reaches around the SIJ and the surrounding para-spinal muscles, and subsequently reduces the ongoing inflammation. Corticosteroids may be administered through the intra-articular route to decrease the intensity and duration of pain [19]. Scholten et al. [20] confirmed that fluoroscopically guided corticosteroid injections, based on arthrographic contrast patterns, into the superior portion of SIJ were effective in de-

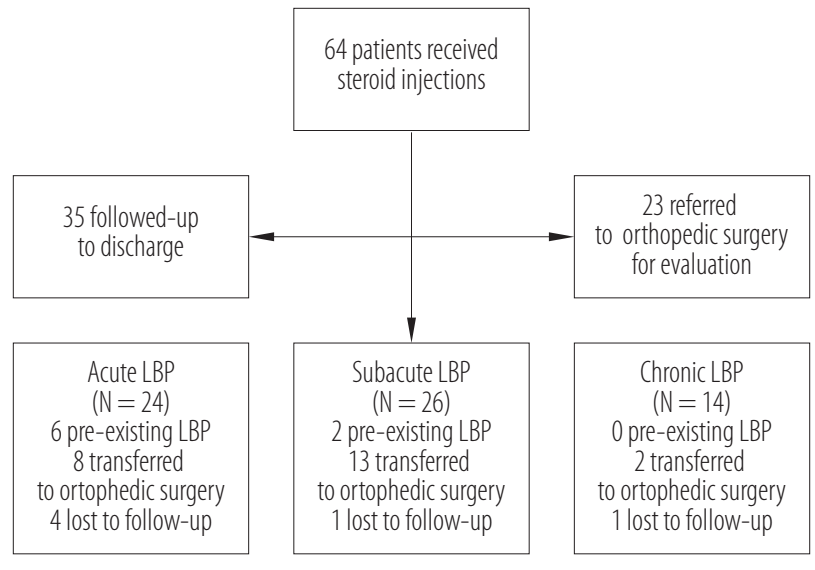

Figure 3. Flow chart for the study

creasing self-reported numeric pain rating values in patients with SIJ-related pain. Some studies have found that intraarticular SIJ injections provide good-to-excellent pain relief, lasting up to 1 year [21]. Other studies have shown that periarticular injections are beneficial as well [21]. However, 1 study has found a moderate evidence for short-term SIJ pain relief and limited evidence for the long-term perspective [22].

The authors used a unique method to deliver the periarticular steroid injection, which does not necessarily require imaging guidance. This approach attempts to perform the SIJ injection directly, but the injection needle is also redirected so as to involve not only the peri-articular structures of SIJ (the capsule and ligaments), but also the lower lumbar para-spinal muscles where the physical examination elicited maximum tenderness. The unique anatomy of SIJ, with a weak anterior capsule and strong posterior ligaments, makes it difficult to distinguish between intra-articular and extra-articular pathologies [23]. Additionally, accurate intra-articular injections are usually difficult to obtain [21]. Rosenberg et al. [24] showed that the targeted intra-articular injection was actually achieved in only $22 \%$ of patients when clinicians used the palpation-only technique (without imaging guidance).

The ACOEM guidelines have no documented demonstration of improved SIJ pain after the injection to the soft tissues around SIJ, yet these results show a significant reduc- 
Table 2. Characteristics of the discharged and transferred patients who received a sacroiliac joint steroid injection in April 2013-March 2018 at the Loma Linda University Medical Center, Loma Linda, USA

\begin{tabular}{|c|c|c|c|}
\hline \multirow{2}{*}{ Variable } & \multicolumn{2}{|c|}{$\begin{array}{l}\text { Participants } \\
(\mathrm{N}=58)\end{array}$} & \multirow{2}{*}{$\mathrm{p}$} \\
\hline & $\begin{array}{c}\text { discharged } \\
(\mathrm{N}=35)\end{array}$ & $\begin{array}{c}\text { transferred } \\
(\mathrm{N}=23)\end{array}$ & \\
\hline Age [years] $(\mathrm{M} \pm \mathrm{SD})$ & $43.7 \pm 12.1$ & $37.9 \pm 11.5$ & 0.07 \\
\hline Women $[\mathrm{n}(\%)]$ & $26(74)$ & $16(70)$ & 0.69 \\
\hline $\mathrm{BMI}(\mathrm{M} \pm \mathrm{SD})$ & $31.9 \pm 6.8$ & $29.2 \pm 4.9$ & 0.126 \\
\hline History of mental health disease (yes) $[\mathrm{n}(\%)]$ & $10(29)$ & $5(22)$ & 0.56 \\
\hline Initial pain level $(\mathrm{M} \pm \mathrm{SD})$ & $6.5 \pm 2.1$ & $5.8 \pm 2.2$ & 0.308 \\
\hline Duration of symptoms before the steroid injection [days] $(\mathrm{M} \pm \mathrm{SD})$ & $78 \pm 91$ & $54 \pm 51$ & 0.258 \\
\hline Taking narcotics (yes) $[\mathrm{n}(\%)]$ & $12(46)$ & $15(65)$ & 0.181 \\
\hline Degenerative disc disease of the lumbar spine in MRI (yes) [n (\%)] & $5(19)$ & $12(52)$ & 0.016 \\
\hline
\end{tabular}

BMI - body mass index; MRI - magnetic resonance imaging.

tion of symptoms after using this technique. The rates of return to regular duty and the release from care (discharge) were relatively high, compared to the transfer rate, especially among the subacute and chronic LBP groups. None of the involved patients reported any side effects. The cost of a triamcinolone injection is also considered negligible compared to the benefit of returning to work early.

\section{Limitations}

The strengths of this study include the rigorous inclusion criteria (confined only to work-related LBP or SIJ pain) and the comparison of the outcome in a sample population, which eliminates confounding and interpersonal variability. The weaknesses include a retrospective study design without a control group receiving placebo injections for comparison. This study did not have a group exclusively managed on conservative treatment to document the natural progression of work-related back pain until discharge. All the patients received a steroid injection at both the SIJ and the para-spinal muscles when some of them had pain or injury at only 1 site. Although previous studies had shown that overweight and obesity might delay recovery for LBP, this study did not find any statistically significant difference in the mean BMI between the discharged and transferred groups. These findings could be attributed to the small sample size which was used in this study.

The recorded data on pre-existing baseline pain were subjective and may have introduced some recall bias. Once a patient resumed regular duty and got discharged from the clinic, there was no scheduled long-term follow-up. This limited the authors' ability to assess the long-term effectiveness of the steroid injection. However, since they did not have any revisits to the clinic after discharge, they assumed that the discharged patients did not have any recurrence for their symptoms, at least for the past 6 months (the duration between the last follow-up and the preparation of this paper). Although these findings are preliminary, the authors recommend a large-sample randomized control trial to further investigate the efficacy of corticosteroid injections for work-related LBP.

\section{CONCLUSIONS}

Blind corticosteroid injections into the proximity of SIJ and the para-lumbar spinal muscles constitute a safe effective 
treatment in managing LBP for patients who do not respond to conservative treatment and do not have concurrent lumbar spine pathology. Steroid injections provide near-immediate pain relief for LBP and facilitate an earlier return to regular duty. Despite certain limitations, the authors do recommend peri-articular and intra-muscular corticosteroid injections for patients with work-related LBP and SIJ pain who do not respond to conservative management.

\section{ACKNOWLEDGMENTS}

Special thanks and acknowledgment for Stephanie Fan (Electronic Medical Records, Loma Linda University Medical Center) for the help with the data extraction from the electronic medical records which were utilized for the research. Also for Dr. Haitham Juma MD MPH (Associate Professor of Occupational Medicine, Loma Linda University) who helped with providing clinical cases, ideas and suggestions for the research. Thanks also to Jose Binongo PhD (Associate Professor of Biostatistics, Emory University School of Public Health) who helped with the data analysis.

\section{REFERENCES}

1. Bernard BP, editor. Musculoskeletal Disorders and Workplace Factors. A Critical Review of Epidemiologic Evidence for Work-Related Musculoskeletal Disorders of the Neck, Upper Extremity, and Low Back. Cincinnati: National Institute for Occupational Safety and Health; 1997.

2. Centers for Disease Control and Prevention. Prevalence of disabilities and associated health conditions among adults United States, 1999. JAMA. 2001;285(12):1571-2.

3. Vos T, Flaxman AD, Naghavi M, Lozano R, Michaud C, Ezzati M, et al. Years lived with disability (YLDs) for $1160 \mathrm{se-}$ quelae of 289 diseases and injuries 1990-2010: a systematic analysis for the Global Burden of Disease Study 2010. Lancet. 2012;380(9859):2163-96.

4. Shraim M, Cifuentes M, Willetts JL, Marucci-Wellman HR, Pransky G, et al. Length of Disability and Medical Costs in Low Back Pain: Do State Workers' Compensation Policies Make a Difference? J Occup Environ Med. 2015;57(12):1275-83.
5. U.S. Department Of Health And Human Services, National Institutes of Health. Low Back Pain. Low Back Pain Fact Sheet [Internet]. Bethesda, Maryland: National Institute of Neurological Disorders and Stroke; 2013 [cited 2019 Dec 20]. Available from: https:/www.ninds.nih.gov/sites/default/files/ low_back_pain_20-ns-5161_march_2020_508c.pdf.

6. Yang H, Haldeman S, Lu M-L, Baker D, et al. Low Back Pain Prevalence and Related Workplace Psychosocial Risk Factors: A Study Using Data From the 2010 National Health Interview Survey. J Manipulative Physiol Ther. 2016;39(7):459-72.

7. McLaren CF, Baldwin ML, Boden LI, Worker's Compensation: Benefits, Costs and Coverage (2016 Data). Washington: National Academy of Social Insurance; 2018.

8. Zhao X, Watson M, Workers Compensation Research Institute. The Anatomy of Workers' Compensation Medical Costs and Utilization. Cambridge (MA): Workers Compensation Research Institute; 2007.

9. Webster BS, Snook SH. The cost of 1989 workers' compensation low back pain claims. Spine (Phila Pa 1976). 1994;19(10):1111-5, discussion 1116.

10. Atlas SJ, Chang Y, Keller RB, Singer DE, Wu YA, Deyo RA. The impact of disability compensation on long-term treatment outcomes of patients with sciatica due to a lumbar disc herniation. Spine (Phila Pa 1976). 2006;31(26):3061-9, https://doi.org/10.1097/01.brs.0000250325.87083.8d.

11. Wynne-Jones G, Cowen J, Jordan JL, Uthman O, Main CJ, Glozier N, et al. Absence from work and return to work in people with back pain: a systematic review and meta-analysis. Occup Environ Med. 2014;71(6):448-56.

12. Hegmann KT, editor. Low Back Disorders [Internet]. Elk Grove Village: American College of Occupational and Environmental Medicine; 2016 [cited 2019 Dec 20]. Available from: https://www.dir.ca.gov/dwc/MTUS/ACOEM-Guidelines/Low-Back-Disorders-Guideline.pdf.

13. Knezevic NN, Mandalia S, Raasch J, Knezevic I, Candido KD, et al. Treatment of chronic low back pain - new approaches on the horizon. J Pain Res. 2017;10:1111-23, https://doi.org/10.2147/JPR.S132769. 
14. Sardana V, Burzynski J, Hasan K, Zalzala P. Are non-steroidal anti-inflammatory drug injections an alternative to steroid injections for musculoskeletal pain? A systematic review. J Orthop. 2018;15(3):812-6.

15. Thiese MS, Hegmann KT, Wood EM, Garg A, Moore JS, Kapellusch J, et al. Prevalence of low back pain by anatomic location and intensity in an occupational population. BMC Musculoskeletal Disorders. 2014;15(1):283, https://doi.org/ 10.1186/1471-2474-15-283.

16. Cohen SP. Sacroiliac joint pain: a comprehensive review of anatomy, diagnosis, and treatment. Anesth Analg. 2005;101(5):1440-53.

17. Gupta AD. Sacroiliac joint pathologies in low back pain. J Back Musculoskelet Rehabil. 2009;22(2): 91-7, https://doi. org/10.3233/BMR-2009-0221.

18. Kennedy DJ, Engel A, Kreiner DS, Nampiaparampil D, Duszynski B, MacVicar J. Fluoroscopically Guided Diagnostic and Therapeutic Intra-Articular Sacroiliac Joint Injections: A Systematic Review. Pain Med. 2015;16(8):1500-18, https://doi.org/10.1111/pme.12833.

19. Bhattacharjee DP, Biswas C, Haldar P, Ghosh S, Piplai G, Rudra JS. Efficacy of intraarticular dexamethasone for postoperative analgesia after arthroscopic knee surgery. J Anaesthesiol Clin Pharmacol. 2014;30(3):387-90, https:/doi. org/10.4103/0970-9185.137273.
20. Scholten PM, Patel SI, Christos PJ, Singh JR. Short-term efficacy of sacroiliac joint corticosteroid injection based on arthrographic contrast patterns. PM R. 2015;7(4):385-91, https://doi.org/10.1016/j.pmrj.2014.10.007.

21. Soto Quijano DA, Otero Loperena E. Sacroiliac Joint Interventions. Phys Med Rehabil Clin N Am. 2018;29(1):171-83, https://doi.org/10.1016/j.pmr.2017.09.004.

22. McKenzie-Brown A, Shah R, Sehgal N, Everett C. A systematic review of sacroiliac joint interventions. Pain Physician. 2005;8(1):115-25.

23. Thawrani DP, Agabegi SS, Asghar F. Diagnosing Sacroiliac Joint Pain. J Am Acad Orthop Surg. 2019;27(3):85-93, https://doi.org/10.5435/JAAOS-D-17-00132.

24. Rosenberg JM, Quint TJ, de Rosayro AM. Computerized tomographic localization of clinically-guided sacroiliac joint injections. Clin J Pain. 2000;16(1):18-21, https:/doi. org/10.1097/00002508-200003000-00004.

25. Abate M, Salini V, Schiavone C, Andia I. Clinical benefits and drawbacks of local corticosteroids injections in tendinopathies. Expert Opin Drug Saf. 2017;16(3):341-9, https:// doi.org/10.1080/14740338.2017.1276561.

26. Furtado RN, Oliveira LM, Natour J. Polyarticular corticosteroid injection versus systemic administration in treatment of rheumatoid arthritis patients: a randomized controlled study. J Rheumatol. 2005;32(9):1691-8.

This work is available in Open Access model and licensed under a Creative Commons Attribution-NonCommercial 3.0 Poland License - http://creativecommons.org/ licenses/by-nc/3.0/pl/deed.en. 